\title{
16. THE IMPACT OF TRANSFORMATIVE LEARNING ON SOCIAL TRANSFORMATIONS
}

\author{
A Comparative Study of Participatory Budgets in Maribor (Slovenia) \\ and Rosario (Argentina)
}

\section{INTRODUCTION}

With the current economic and financial crisis, global capitalism is becoming increasingly barbaric, bringing us closer towards planetary social war and societal fascism (de Sousa Santos, 2014). Under these circumstances counter-tendencies and alternative practices which prefigure a post-capitalist world assume enormous importance. Arguably, participatory budgeting (PB) is one of these practices. PB is most often defined as a democratic practice of deliberation and decision-making in which community members in assemblies directly decide how to spend part of the public budget (Cabannes, 2004; Baiocchi, 2005; Sintomer et al., 2014). This creates a system of co-governance (de Sousa Santos, 2005) in which "self-organized" citizens and engaged civic society exert public control over the municipality "by means of institutionalized forms of cooperation and conflict" (p. 308). This chapter will explore $\mathrm{PB}$ as a transformative democratic learning process.

First developed in 1989 in Porto Alegre, Brazil, PB has spread variably all over the continent and the world. PB is effective in strengthening democratic processes in local communities, as well as its capacity to afford opportunities for the most marginalized and vulnerable social groups to participate in co-governance (Baiocchi, 2005; de Sousa Santos, 2005; Schugurensky, 2006, 2013).

PB also became a widely used and effective participatory 'bottom-up' democratic practice promoted by transnational political and financial institutions (World Bank, United Nations, OECD, UNESCO, USAID, and EU) which started to implement their own version of PB (Gregorčič \& Jelenc Krašovec, 2017). However, they were primarily interested in the technocratic virtues of $\mathrm{PB}$ (the efficiency and effectiveness of resource distribution and utilization), but not in its democratic possibilities that has led to the creation of a complex system of participation and distributive justice (de Sousa Santos, 2005, p. 357). It is noteworthy that the cities that established PB according to the terms set by transnational institutions never achieved the same democratic impact that can be seen in Porto Alegre (de Sousa Santos, 2015), or the Argentinian city of Rosario or in the Slovenian city of Maribor where PB emerged from 'below'. This chapter will explore what has occurred in Rosario and Maribor 
in terms of power, participation and adult learning and specifically transformative learning in relation to social transformation.

\section{PARTICIPATORY BUDGETING AS A PEDAGOGICAL PROCESS}

Many educators recognize that important learning takes place through involvement in social activities (Foley, 1999; Hall et al., 2012; Vieta, 2014) and/or in participatory democratic processes (Schugurensky, 2006; McLaren \& Farahmandpur, 2001; Salgado, 2015; Pateman, 1988). Building on this literature this contribution will highlight two pedagogical aspects of PB practices: the importance of 'two-way pedagogy' and the importance of participatory democratic practices in fostering both personal and social transformation.

Schugurensky (2002, p. 12) views PB as political-pedagogical process and emphasizes the centrality of reciprocity in participatory democracy and transformative learning: transformative learning can promote participative democracy, but participative democracy also has the potential to nurture transformative learning. Likewise, de Sousa Santos describes the learning process in PB as a "two-way pedagogy" (2005, p. 362) that take place between active citizens and NGOs on the one hand, and administrative and technical civil servants of a city or municipality on the other. This is partly because there is exceptional potential for learning among the civil servants when an attempt is made to transition away from conservative forms of techno-bureaucratic culture (de Sousa Santos, 2005). Within transformative democratic practices, pedagogical aspects can be seen in the process of teaching about democracy with the method of learning-by-doing, community learning within social institutions (self-organized or in pre-existing institutions with and without an educational remit). De Sousa Santos (2005) found that participation in democratic processes grew and intensified when the scope and complexity of models which constitute PB expanded as well.

This is some of the background for our comparative study. The transformative impact of PB, which began in 1995, on the citizens of Rosario has been researched by Lerner and Schugurensky (2007) and our work further advances this. The study in Maribor was conducted between the end of 2015 and the beginning of 2016 (Gregorčič \& Jelenc Krašovec, 2017). PB in Maribor developed as a response to the degenerating political situation in the city and derived directly from popular uprisings started in Maribor in November 2012, which spread all over Slovenia, resulting in the resignation of Maribor's mayor and the national government in the beginning of 2013. It has since spread to five other Slovenian towns.

\section{TRANSFORMATIVE LEARNING IN PARTICIPATORY PROCESSES}

To explore in what ways PB has been transformative we want to draw on transformative learning theory. Jack Mezirow, who based his work on Freire's concept of conscientização and Habermas' theory of communicative action, 
THE IMPACT OF TRANSFORMATIVE LEARNING ON SOCIAL TRANSFORMATIONS

Table 16.1. Categories of transformative learning

\begin{tabular}{lll}
\hline O'Sullivan, Morrel, \& O'Connor & Hoggan & Lerner \& Schugurensky \\
\hline Shift in basic premises and thought & Worldview & Knowledge \\
Shift in feeling & Self & Values and attitudes \\
Shift in action & Epistemology & Skills \\
Shift in consciousness & Ontology & Practices \\
Altered way of being in the world & Behaviour & \\
& Capacity & \\
\hline
\end{tabular}

understood transformative learning as a process in which an individual is elaborating the existing frame of reference, learning a new frame of reference, transforming points of view, and transforming habits of mind (Mezirow, 1991; Mezirow \& Taylor, 2009).

There is no single or predominant definition on the impact of transformative processes among the scholars of transformative learning. Table 16.1 summarizes three attempts by pedagogues to explore possible ways of 'measuring' or 'proving' transformative learning has taken place. O'Sullivan, Morrel, and O'Connor (2002) define transformative learning within five basic categories that range from shifts in basic premises and thoughts to a wider, cosmopolitan perception of the world. These categories correspond with the changing frame of reference measured in four categories by Lerner and Schugurensky (2007) and the six categories offered by Hoggan (2016). He emphasizes that the parameters of determining transformative learning should focus more on the scope of learning than on the type of change in the learning outcome (Hoggan, 2016, p. 79), while Lerner and Schugurensky (2007) place more importance on the domain of the change and determining whether it occurred at all.

Mezirow (1991) argues that there are certain preconditions for transformative learning - rational, critical dialogue, critical self-reflection, maturity and emotional intelligence. Most agree that democratic discourse is especially central to transformative learning (Mezirow, 1991; Schugurensky, 2002, 2006, 2013; Illeris, 2014; Hoggan, 2016; Dirkx, 1998).

Mezirow presents transformative learning as something which first and foremost occurs on a biographical level may or may not lead to social action or wider social change (Finnegan, 2014, p. 4). In the case of Maribor and Rosario the processes of social, community and individual transformation were inextricably linked and occurred in more unpredictable way than is often imagined in transformative learning theory. The research indicates that there was rich "learning through struggle" (Foley, 1999), and "learning in struggle" (Vieta, 2014; Gregorčič, 2017) which is profoundly transformative and was led by the marginalized and oppressed, and sparked by participation in self-organized and autonomous struggles and through deliberation 
and decision-making practices. One of the main arguments of this chapter is that the process of participatory democracy is itself an important learning experience for different areas of life, and that it is not only relevant for the identification of new knowledge acquired by participants in such processes, but also because of the 'way' in which the participants learned and transformed on a personal level, as well as the wider social changes that they produced in the process (see also Lerner \& Schugurensky, 2007).

\section{BRIEF NOTES ON METHODOLOGY}

The comparative study of learning within PB in Maribor and Rosario presented here is based on the model developed at the Ontario Institute for Studies in Education (OISE) that explores changes through learning in four categories (knowledge, values and attitudes, skills, and practices, or KASP). Research on learning and deliberative practices has been systematically researched at OISE and is very compatible with the theories of transformative learning discussed above. The Rosario case study is based on ethnographic research, which included 40 in-depth interviews and observation with participation in 12 assemblies as well as drawing on other in-depth research on PB practices made by Schugurensky. Extensive qualitative research was carried out in Maribor as well. It included active participation in the assemblies in the first three months and observation of the process from the beginning to the present; a focus group in one assembly; and 12 semi-structured interviews.

There were some differences in methodological processes between the two studies as the Rosario interviewees assessed the indicators across 55 items twice (once before entering the PB practice and once afterwards), while the interviewees in Maribor assessed the change or shift across 70 items only once. Also, interviewees in Rosario had been involved in active community practices for a longer period (from 1995), while interviewees in Maribor barely started (from 2012). Indicators in Maribor were adapted to Slovenian context, thus not all indicators were used across both case studies. Besides which the historical, institutional, political and learning context are very different in Slovenia and Argentina.

The KASP changes presented in the next section in Tables 16.2, 16.3, 16.4, and 16.5 show the average value increase for each indicator, measured on a five-point Likert scale, but not the quality of the change. As a result, an interviewee could have significantly improved their previous specific knowledge within the PB activities, and another could have just started developing or learning new or specific knowledge. The values only reflect the interviewees' perception of change. In interpretations of the results we also used four other research methods, focusing on personal stories, learning situations and the changes that interviewees mentioned during discussion.

Despite these methodological differences we think it is relevant to analyze across contexts what changes (if any) occurred, what were the areas of change and which learning practices were considered the most important by the interviewees. We also assessed whether the interviewees experienced transformative learning, how this 
was reflected in their self-transformation and whether their KASP changes has an impact on social transformation.

\section{TRANSFORMATIVE LEARNING IN ROSARIO AND MARIBOR}

The results point to the transformative impact of $\mathrm{PB}$ in Maribor and Rosario similar to those documented in Porto Alegre, Montevideo, Toronto, and other cities with PB (Lerner \& Schugurensky, 2007; Schugurensky, 2013). Interviewees acquired instrumental and technical knowledge of co-management, politics and citizenship, developed analytical, leadership and deliberative skills, enhanced understanding of the importance of the commons and community care, increased tolerance and respect towards the oppressed and the marginalized, and ultimately and most importantly, they transferred new understanding, knowledge, skills, values and attitudes to new social practices, contexts and activities (Gregorčič \& Jelenc Krašovec, 2017). In addition to specific knowledge and skills (improving self-expression, using social media and creating radio shows, magazines, etc.), active citizens also began to practice public speaking and performance, wrote public letters, organized public meetings, protests and demonstrations.

The biggest change in Rosario was in terms of knowledge of "people from other neighborhood and organizations" and new knowledge of city government and familiarity with the local communities or neighborhood (Table 16.2). The results

Table 16.2. Acquiring new knowledge

\begin{tabular}{lcc}
\hline Indicators of knowledge (the average value increase)* & Maribor & Rosario \\
\hline Knowledge of management and work of public enterprises & 1.7 & $* *$ \\
Understanding of needs of own community or group & 1.6 & 1.7 \\
Understanding of needs of other communities & 1.6 & 1.4 \\
Knowledge of discussion necessary for consensus building & 1.5 & $* *$ \\
Knowledge of 'active' listening in the assemblies & 1.5 & $* *$ \\
Knows people from other neighborhood and organizations & $* *$ & 1.9 \\
Knowledge of criteria/mechanisms used to allocate public funds & 1.2 & 1.5 \\
Personally knows elected politicians & $* *$ & 1.4 \\
Knowledge of city government & 1.0 & 1.7 \\
Awareness of citizen rights and duties & 0.8 & 0.9 \\
\hline
\end{tabular}

* Interviewees ranked indicators on a five-point Likert scale, where in the case of Rosario 1 represented the smallest change and 5 the biggest, but in Maribor value 3 was the baseline estimate, i.e. the value of each indicator prior participating in the PB, while $<3$ marked the level of negative and $>3$ the level of positive change.

** Indicators that were defined differently in Rosario and Maribor and thus cannot be compared. 
indicate the emergence of a new techno-bureaucratic culture (de Sousa Santos, 2005) created by the long-lasting and intensive two-way pedagogical practice between the self-organized citizens and non-governmental organizations on the one hand, and the political establishment of the city on the other. This was reflected in the high levels of trust for local politicians. However, this two-way pedagogical process had not been established in Maribor even after five years of deliberative practices despite the best efforts of active citizens because of double-dealing by politicians and resistance to change amongst municipal officials

Rosario showed a balanced change with respect to all areas of research - including practice - whereas the changes in Maribor were most prominent in the area of knowledge (see Table 16.2). Results differ, we think, because the PB in Rosario has been long-lasting and stable but also because differing processes of socio-political governance and management in Maribor.

In Maribor "knowledge of management and work of public enterprises" was the most strongly emphasized. Public enterprises are still responsible for providing services in Maribor such as water and basic living goods, which makes this indicator very relevant. The working group Self-organized council for the protection of the users of public goods - citizen control has developed into a city institution. The reciprocal process of self-organization and self-learning that the citizens developed into many such new informal institutions led to visible results: interviewees increased their critical awareness and knowledge about the functioning of municipality and they emphasized that they lost their "uneasiness" or "awe of decisionmakers in municipality" as they began to recognize ignorance, incompetence and manipulation of the municipality's officials after carefully examining specific areas and problems. Interviewees strongly identified with collective initiatives and with the representatives that they appointed for specific assignments within their assemblies.

Participation in the PB deliberative practice was strongly influenced the values and attitudes of interviewees in both cities (Table 16.3). While the collective transformation of the community was more pronounced in Rosario, selftransformation was strongly emphasized in Maribor. The unplanned and unexpected personal transformation of citizens in Rosario reflected most strongly in self-reliance and affiliation with the neighbors and with the community while the changed attitudes and values also affected personal and family life of the active citizens in Maribor. Personal reflections of the changes can be seen in the statements "I am happier now than I was before" and "this initiative made me realize that I can change something". Transformative impact was also expressed by in phrases such as feeling a "new [sense of] belonging", "a new place in the society", and in relation to the social capital that citizens gained through making new acquaintances and through socializing, and even "finding a new family" for younger participants.

Schugurensky (2013, p. 168) discussed the integration processes established by the PB in Rosario through the concept of "bonding social capital" and "bridging social capital". The latter emphasizes the cooperation of people with very different 
Table 16.3. Transformation through the change in values and attitudes

\begin{tabular}{lcc}
\hline Indicators of attitudes and values (the average value increase) & Maribor & Rosario \\
\hline Appreciate citizens participation more than before & 1.5 & $* *$ \\
Feeling of "being heard" & 1.5 & $* *$ \\
Ability to resolve conflicts & 1.3 & 0.7 \\
Double the number of friends & 1.3 & $* *$ \\
Concern for the problems of the city & 1.3 & 1.3 \\
Confidence in capacity to influence political decisions & 1.3 & 1.2 \\
Tolerance and respect for others & 1.1 & 0.7 \\
Happier than before & 1.1 & $* *$ \\
Concern for the problems of the neighborhood & 1.0 & 1.2 \\
Increased respect for people/social groups (Roma, LGBTQ, etc.) & 1.0 & $* *$ \\
Interest in community participation & 0.9 & 1.0 \\
Self-confidence & 0.9 & 0.9 \\
Feel connected to neighbors & 0.8 & 1.0 \\
Sense of responsibility for the preservation of the city & 0.6 & 0.9 \\
\hline
\end{tabular}

* Please see note at bottom of Table 16.2 for explanation of scale.

** Indicators that were defined differently in Rosario and Maribor and thus cannot be compared.

life histories and above all with high inequality in income and belonging to different communities (bridging the differences between citizens from poor areas and elite neighborhoods). inequality in Slovenia is significantly lower than in the cities of Argentina or Latin America in general, and as such, 'bridging social capital' came in the form of intergenerational cooperation and reciprocity. The older interviewees expressed their self-transformation due to participation in democratic practices as "rejuvenating" thanks to the younger members, evident in statements "I am alive again" and "I am energetic again". The younger participants emphasized the support and affection of the elderly, having felt "protected for the first time", gaining a circle of people they can "rely on", etc. This was a unique experience for both generations, who had not experienced this in previous social activities to the same extent. As in Rosario, interviewees emphasized reciprocity, collectivism, community or bonding social capital, as well as their own transformation in understanding work: "finally I am doing something useful", "I created my employment from the PB initiative", "I am finally trying to do something with my life".

Tolerance and respect for the marginalized and excluded social groups were also important in Maribor; interviewees emphasized new understanding of the Roma people, migrants and other marginalized groups that they did not previously cooperate with, and mentioned several ways they addressed local issues. In 2015 
Table 16.4. Acquiring new skills

\begin{tabular}{lcc}
\hline Indicators of skills (the average value increase)* & Maribor & Rosario \\
\hline Ability to rank and prioritize demands & 1.5 & 1.4 \\
Ability to engage in teamwork and cooperation & 1.5 & 0.8 \\
Ability to make collective decisions & 1.5 & 1.1 \\
Ability to achieve consensus & 1.4 & $* *$ \\
Ability to solve conflicts & 1.4 & 0.8 \\
Ability to listen carefully to others & 1.4 & 0.7 \\
Ability for intergenerational exchange & 1.3 & $* *$ \\
Ability to speak in public with clarity & 1.3 & 1.0 \\
Ability to build an argument, to argue, persuade & 1.3 & 0.9 \\
Ability to negotiate, bargain, build alliances & 1.1 & 1.1 \\
Ability to monitor and keep track of actions of city government & 1.1 & 1.9 \\
Ability to contact government agencies and officials & 1.1 & 1.6 \\
Ability to relate to neighbors & 1.0 & 0.9 \\
Ability to understand and interpret official documents & 0.9 & 1.0 \\
Ability to develop and defend proposals and projects & 0.9 & 1.2 \\
Ability to plan and organize meetings & 0.7 & 0.9 \\
\hline
\end{tabular}

* Please see note at bottom of Table 16.2 for explanation of scale.

** Indicators that were defined differently in Rosario and Maribor and thus cannot be compared.

they supported the migration corridor of refugees with solidarity campaigns; in the same year they also responded to the referendum on the amendment to the Marriage and Family Relations Act (although they had previously never engaged politically on the issues of same-sex partnerships); they opposed the initiatives that aimed to prevent the first Roma restaurant in the city in 2013, etc.

Furthermore, the self-organized citizens in Maribor, as in Rosario, began to place more importance on the common goods and the needs of the most rmarginalized groups than on individual interests. They began fighting for recognition, social justice, solidarity, and individual and common welfare; many researchers of transformative learning highlight this as the most important change or impact of transformative learning (Hoggan, 2016; Lerner \& Schugurensky, 2007, Schugurensky, 2013; Curry-Stevens, 2007). Thus, as acknowledged by Schugurensky (2002), transformative learning can improve the quality of citizens' participation in democratic institutions and consequently quality of life in the broader society, but at the same time democratic participation itself creates powerful opportunities for self-transformation identified in Maribor and Rosario. 
Table 16.5. Transformative practices

\begin{tabular}{lcc}
\hline Indicators of practices (the average value increase) $^{*}$ & Maribor & Rosario \\
\hline Write public letters, petitions, argument problems for the media & 1.4 & $* *$ \\
Propose ideas/solutions for community problems & 1.4 & 1.1 \\
Strengthen intergenerational cooperation & 1.3 & $* *$ \\
Discuss problems in the area with the neingbors & 1.0 & 1.2 \\
Think up ideas and solutions for community problems & 1.0 & 1.3 \\
Monitor and keep track of the public budget & 0.9 & 1.6 \\
Monitor and keep track of the quality of public works & 0.9 & 1.6 \\
Attend community meetings & 0.9 & 1.3 \\
Participate actively on community meetings & 0.9 & 1.2 \\
Talk to city councillors and other elected politicians & 0.9 & 1.2 \\
Seek out information about political and social issues & 0.9 & 1.0 \\
Organize protests, working actions, direct actions & 0.7 & $* *$ \\
Help to keep the city clean and in good repair & $* *$ & 0.6 \\
\hline
\end{tabular}

* Please see note at bottom of Table 16.2 for explanation of scale.

** Indicators that were defined differently in Rosario and Maribor and thus cannot be compared.

In addition to intergenerational cooperation, consensus decision making, active listening and analytical skills, and teamwork were more prominent in Maribor than in Rosario (Table 16.4). Interviewees developed the ability to formulate and defend proposals, understand official documents, find relevant information and other social skills and leadership abilities. The ability to monitor and keep track of actions of city government and to contact government agencies and officials were more prominent in Rosario, although both indicators were highly ranked $(>1)$ in Maribor as well. Schugurensky's research has shown that one of the most frequently acquired new skills is the ability to identify priorities and rank demands for the community.

Practice was the least mentioned and lowest ranked field of all KASP changes in Maribor, but the research has shown that interviewees were often involved in direct actions and lobbying (public letters, petitions, press conferences, discussing problems in the area with neighbors, monitoring the work of civil servants and tracking the public budget, organizing protests, etc.) (Table 16.5). Interviewees highlighted the importance of non-hierarchical and egalitarian relations, "strategic thinking", "a greater focus on the problem", "a toolbox of tactics for achieving objectives". They managed to force the mayor to proclaim the town a "TIPP free zone' (against the Transatlantic Trade and Investment Partnership planned by EU and USA) as well as encouraging many other cities, municipalities and their mayors in Slovenia to do the same, demonstrating a understanding of the global politics, 
which many scholars recognize as an important aspect of transformative learning (Hoggan, 2016; O’Sullivan, Morrel, \& O’Connor, 2002).

The majority of interviewees in Rosario similarly emphasised that as a result of PB, they now do things they had never done before (Schugurensky, 2013, p. 171) and that they moved from a culture of protest and confrontation to a culture of conflict and negotiation (de Sousa Santos, 2005, p. 335). Such libertarian horizontal practices raise doubts about rooted attitudes and habits and open up new opportunities for participation and action; they become important sites for critical learning and developing critical awareness, as emphasized by Freire (conscientização). These horizontal practices offer a number of opportunities, from less authoritarian and excluding behavior to learning of active citizenship - as well as learning and implementing civil disobedience tactics when authorities do not respond to other democratic measures.

\section{CONCLUSION}

The comparative study of PB in Rosario and Maribor indicates that participation in such processes results in transformative learning and wider social transformations which profoundly affects the quality of life and well-being of all participants in selforganized communities. PB is not only a technocratic and democratic solution that contributes to a more transparent, efficient, just and democratic way of governing cities, but it also creates privileged learning sites, spaces for meeting and cooperation (Schugurensky, 2006, 2013). These spaces address civic and political aspects of change, such as solidarity, tolerance, openness, accountability, and respect, and also develop social and cultural capital and thus give active citizens the capability to co-govern cities and influence political decisions (Lerner \& Schugurensky, 2007).

The pedagogical value of the PB practice, its ability to build bottom-up, autonomous learning communities, is one of the most important impacts on the wider local community. As can be seen in Maribor and Rosario, learning and creation of PB practices as a bottom-up approach incites dialogue and critical reflection or conscientização, two fundamental elements of transformative learning. Learners in Maribor and Rosario constructed PB responding to authentic and realistic needs within their specific contexts and therefore their knowledge was not inert, decontextualized, pre-determined or alienated from the community and their own lives. Through assemblies based on horizontal communication and the enhanced 'critical literacy' they also managed to develop more emancipatory and just forms of co-governance. It also increased the bonding and bridging social capital and concrete political actions and interventions (political capital) that resulted from the commitment of active participants. This was possible because the PB participants in Maribor and Rosario, unlike in other cities with PB, went through an extensive process of transformative learning; their activities were implemented directly, faceto-face (and not through digital forums), continuously, on regular weekly assemblies led in a bottom-up way by the active members of the self-organized process. 
As a result, the participants began a powerful process of liberation within a community; they managed to create 'real' democratic spaces without any assistance of city authorities and public institutions and despite all the obstacles posed to the selftransformative process. In these spaces, people are allowed, and even encouraged and empowered, to learn, explore, consult about, experiment and transform participatory democracy. Precisely because of the pedagogical aspects highlighted in this study, Maribor and Rosario - without planning and almost unintentionally - established an informal network of educational institutions; safe, autonomous and emancipated sites where everyone is heard, respected and encouraged to resolve wider social issues.

In the last decades, creating and nurturing authentic, democratic, learning communities that aspire towards the democratization of existing democratic systems has been recognized as one of the most potent ways of moving beyond capitalism (Hall et al., 2012; Foley, 1999; Vieta, 2014; Gregorčič, 2017; de Sousa Santos, 2014). Our study does not claim that this is the only or the best way, but the practices in Maribor, Rosario, Porto Alegre and elsewhere show that it is a way that enables long-lasting and intense processes of recuperation of communities orientated towards wider social change. Whether the active participants in PB will persist in these processes, whether they will nurture the established learning sites, their 'commons' that appear to the outside to be the greatest contribution of transformative learning, remain open questions that require a new analysis and discussion.

\section{REFERENCES}

Baiocchi, G. (2005). Militants and citizens: The politics of participatory democracy in Porto Alegre. Stanford, CA: Stanford University Press.

Cabannes, Y. (2004). Participatory budgeting: A significant contribution to participatory democracy. Environment and Urbanization, 16, 27-46.

Curry-Stevens, A. (2007). New forms of transformative education: Pedagogy for the privileged. Journal of Transformative Education, 5(1), 33-58.

de Sousa Santos, B. (2005). Participatory budgeting in Porto Alegre: Toward a redistributive democracy. In B. de S. Santos (Ed.), Democratizing democracy. Beyond the liberal democratic canon (pp. 307-376). London: Verso.

de Sousa Santos, B. (2014). Epistemologies of the South: Justice against epistemicide. New York, NY \& London: Routledge.

Dirkx, J. M. (1998). Transformative learning theory in the practice of adult education: An overview. PAACE Journal of Lifelong Learning, 7, 1-14.

Finnegan, F. (2014). Embodied experience, transformative learning and social change: Notes on a theory of social learning. Paper presented at ESREA, Interrogating Transformative Processes in Learning and Education Network, Athens, Greece.

Foley, G. (1999). Learning in social action. A contribution to understanding informal education. London: Zed Books.

Gregorčič, M. (2017). Community learning and learning-by-struggling in solidarity economics. European Journal for Research on the Education and Learning of Adults, 8(2), 207-223.

Gregorčič, M., \& Jelenc Krašovec, S. (2017). Pedagogical dimensions of participatory democracy: Learning through self-organized communities and participatory budgeting in Maribor. In G. A. Koulaouzides \& K. Popović (Eds.), Adult education and lifelong learning in Southeastern Europe (pp. 27-39). Rotterdam, The Netherlands: Sense Publishers. 


\section{GREGORČIČ}

Hall, B. L., Vlover, D. E., Crowther, J., \& Scandrett, E. (Eds.). (2012). Learning and education for a better world: The role of social movements. Rotterdam, The Netherlands: Sense Publishers.

Hoggan, C. (2016). A typology of transformation: Reviewing the transformative learning literature. Studies in the Education of Adults, 48(1), 65-82.

Illeris, K. (2014). Transformative learning and identity. London \& New York, NY: Routledge.

Lerner, J., \& Schugurensky, D. (2007). Who learns what in participatory democracy? Participatory budgeting in Rosario, Argentina. In R. van der Veen, D. Wildemeersch, J. Youngblood, \& V. Marsick (Eds.), Democratic practices as learning opportunities (pp. 85-100). Rotterdam, The Netherlands: Sense Publishers.

McLaren, P., \& Farahmandpur, R. (2001). Educational policy and the socialist imagination: Revolutionary citizenship as a pedagogy of resistance. Educational Policy, 15(3), 343-378.

Mezirow, J. (1991). Transformative dimensions of adult learning. San Francisco, CA: Jossey-Bass.

Mezirow, J., \& Taylor, E. W. (2009). Transformative learning in practice: Insights from community, workplace, and higher education. San Francisco, CA: Jossey-Bass.

Pateman, C. (1988[1970]). Participation and democratic theory. New York, NY: Cambridge University Press.

Salgado, M. (2015). Call this democracy? Education and empowerment through participatory city budgeting. Journal of Urban Regeneration and Renewal, 8(2). 199-209.

Schugurensky, D. (2002). Transformative learning and transformative politics. In E. V. O'Sullivan, A. Morrell, \& M. A. O'Connor (Eds.), Expanding the boundaries of transformative learning (pp. 59-76). New York, NY: Palgrave.

Schugurensky, D. (2006). This is our school of citizenship: Informal learning in local democracy. In Z. Beckerman, N. C. Burbules, \& D. S. Keller (Eds.), Learning in places: The informal educational reader (pp. 163-182). New York, NY: Peter Lang AG.

Schugurensky, D. (2013). Volunteers for democracy: Informal learning through participatory budgeting. In F. Duguid, K. Mündel, \& D. Schugurensky (Eds.), Volunteer work, informal learning and social action (pp. 159-176). Rotterdam, The Netherlands: Sense Publishers.

Sintomer, Y., Herzberg, C., Röcke, A., \& Allegretti, G. (2014). Transnational models of citizen participation: The case of participatory budgeting. In N. Dias (Ed.), Hope for democracy. 25 years of participatory budgeting worldwide (pp. 28-44). São Brás de Alportel: InLoco Editions.

Vieta, M. (2014). Learning in struggle: Argentina's new worker cooperatives as transformative learning organizations. Industrial Relations, 69(1), 186-218. 